\title{
Experimental and numerical study of a falling film absorber in an ammonia-water absorption chiller
}

\author{
Delphine Triché a,b,c , Sylvain Bonnot ${ }^{\mathrm{a}}$, Maxime Perier-Muzet ${ }^{\mathrm{a}}$, François Boudéhenn ${ }^{\mathrm{a}}$, Hélène \\ Demasles $^{\mathrm{a}}$, Nadia Caney \\ a CEA LITEN INES, 50 avenue du Lac Léman, 73375 Le Bourget du Lac, France \\ ${ }^{b}$ Univ. Grenoble Alpes, LEGI, F-38000 Grenoble, CNRS, LEGI, F-38000 Grenoble, France \\ ${ }^{c}$ Agence de l'Environnement et de la Maîtrise de l'Energie 20, avenue du Grésillé - BP 9040649004 Angers Cedex 01, France
}

\begin{abstract}
In this paper,experimental and numerical studies of heat and mass transfer in a falling film absorber are presented. The investigated absorber is a plate heat exchanger used ina falling film configuration. The ammonia-water solution flows in a falling film mode along the plates. The vapour flows co-current with the falling film and the coolant fluid is in a countercurrent flow with the falling film. A prototype of ammonia-water absorption chiller isused to experimentally study the absorber behaviour in real operating conditions. Amacro study of the absorber and a local analysis deduced from local temperatures measurements along the falling film are presented. A numerical model and a simulation tool aredeveloped in order to complete the experimental investigations. The associatednumerical parametric studyaims to separatethe coolant mass flow rate impact.The model is validated with experimental dataand a maximal relative error of $15 \%$ is observedbetween experimental and numerical results. The results of this study suggest that during the absorption process,mass transfers are controlled by the falling film mass transfer resistance and that the liquid-side heat transfer resistance is negligible.
\end{abstract}

Keywords: Falling film absorber; Plate heat exchanger; Ammonia-waterabsorption chiller; Absorber numerical model; Absorption chiller experimental prototype

\section{Introduction}

In the current context of air conditioning democratization, finding an alternative to vapour compression chillers is a major challenge forthe future as it represents approximately $99 \%$ of the today's sold units and it has led to an important increase in electricity consumption and greenhouse gas emissions [1]. Ammonia-water absorption chillers are an alternativesolution as they are thermally driven and generate cooling effect by using environment friendly refrigerant. These chillers are attractive both for solar air conditioning and for industry processes: they make possible the recovery of waste heat released by the industry (heat effluents, exhaust gases). Global demand for absorption chillers market is expected to increase in the next years [2]. However, this technology has to be improved to become competitive in terms of cost and operative behaviour.

Mittermaier and Ziegler [3] showed that the overall performance of absorption machines is mainly influenced by the absorber. Indeed, global performance of the chiller is impacted by low efficiency of the absorber heat and mass transfer process $[4,5]$. As a result, the absorber is one of the most critical components of the absorption chiller in terms of size, cost and efficiency: the understanding of its behaviour is fundamentalto improve global performances of the chiller.

Many studies dealing with the absorption process in ammonia water absorption chillers have been performed with the aim of predicting and increasing heat and mass transfers in the absorber.Those phenomena are widely influenced by absorbers geometries and absorption methods.

The most common absorption methods are bubble absorption [6,7] and falling film absorption. The latter is recommended to improve heat and mass transfers even though thin liquid falling films which completely wet a solid surface are difficult to produce along some materials [8]. Most frequent geometries of absorbers are horizontal tube and vertical tube exchangers; they have been widely studied for different tube diameters [9-14]. But the miniaturization of absorbers is the target of a lot of studies, so the plate heat exchanger is another possible geometry, more compact, for falling film absorption [15-17].

Among performed research, many are either numerical or analytical. The authors established models for the falling film absorption [17-21]. For example, Goel and Goswami [15] analysed a counter current absorber using a finite difference method and empirical correlations for transfer coefficients to understand coupled transfers andGommedet al.[22] used finite volume method to quantify the absorption process.

In a review article dedicated to numerical studies of falling film absorber, Killion and Garimella [23] mentioned that conclusions about the governing transfer resistances are often contentious and pointed out that for ammonia-water working fluid most of the authors neglect mass transfer resistances in vapour phase (considered as pure ammonia) or in liquid phase. In the present work, mass transfer resistances in both liquid and vapour phases are considered to discuss the absorption process. 
Over the last few years, experimental studies have also been performed on the absorber in order to predictitsbehaviour and to determine the limiting transfer's occurrence. Among those, Kang et al.[16] experimentally investigated ammoniawater falling film absorption process. The authors comparethe effect of various operating conditions on heat and mass transfer performances.Kwon and Jeong [24] experimentally studied the effect of the vapour flow direction on the absorption heat and mass transfer in a falling film helical coil absorber.

However, most studies are not performed in real operating conditions. Indeed, some test benches dedicated to the absorption process make possible the study of the absorber but the behaviour of the absorber is separated fromthe oneof the global absorption chiller. Therefore, test conditions at the input of the absorber like pressure, vapour concentration and poor solution concentration, which are conditions dependent on all the elements of the machine, are not representative of real conditions at the input of the absorber in a real absorption chiller [6, 24].

For example, in the work of Kang [16], the method enables operating conditions to vary but the absorber is tested in no representative conditions:the study occults the global chiller behaviour. Indeed, this study was conducted at a vapour concentration varying from $64.7 \%$ to $79.7 \%$ and a solution concentration varying from $5.0 \%$ to $15 \%$ while typical inlet concentrations are rather a vapour concentration of more than $98 \%$ (thanks to the rectification process) and a solution concentration varying from $25 \%$ to $50 \%$.

At the opposite, Nagavarapu and Garimella [9] and Lee et al. [10] considered an absorber on a test facility replicating a functional absorption chiller and showed the importance of all the elements of the machine. Absorbers studied in these works are horizontal-tube falling-film absorbers which were especially designed for the study.

The purpose of the present study is to analyse heat and mass transfer in a plate heat exchanger used as falling film absorber, in order to predict its performances.

A prototype of ammonia-water absorption chiller was used to study the absorber behaviour in real operating conditions. This prototype with a cooling capacity of $5 \mathrm{~kW}$ was built in 2010 and numerous previous tests proved its ability to maintain steady-state conditions [25]. The concerned absorber is a commercial gasketed plate-and-frame heat exchanger used as falling film absorber. This technology wasselected for its compactness and its low cost.

A global analysis at the input and output of the absorber anda local analysis thanks to temperature sensors inside the absorberare possible by means of the experimental device. But this experimental device implies an entire chiller with retroactive effects between the absorber and the other components of the machine. This functioning explains the significant complexity to dissociate variables and their influence on different physical phenomenonandperformances of the absorber.

Thus, to complete this experimental study, a numerical analysis is necessary to controlvariables and to understandthe absorption phenomenon. A modelwas developed and experimentally validated with global and local experimental data in order to facilitatea detailed analysis of heat and mass transfers along the absorber. Finally, anumerical parametric study was conducted to discuss the experimental results. The analysis of the parametric sensitivity study highlights the predominant impact of the coolant mass flow rate variation comparedwith the variation of the other operating parameters.

\begin{tabular}{|c|c|c|}
\hline \multicolumn{3}{|c|}{ Nomenclature } \\
\hline A & Transfer area & {$\left[\mathrm{m}^{2}\right]$} \\
\hline$\Gamma$ & Mass flow per unit length & {$\left[\mathrm{kg} \cdot \mathrm{m}^{-1} \cdot \mathrm{s}^{-1}\right]$} \\
\hline $\mathrm{c}$ & Correction coefficient & {$[-]$} \\
\hline $\mathrm{Cp}$ & Heat capacity & {$\left[\mathrm{J}^{\mathrm{kg}} \mathrm{kg}^{-1} \cdot \mathrm{K}^{-1}\right]$} \\
\hline$\delta$ & Thickness of the falling film & {$[\mathrm{m}]$} \\
\hline $\mathrm{dAi}$ & Interfacial area of the differential control volume & {$\left[\mathrm{m}^{2}\right]$} \\
\hline$\Delta \mathrm{L}$ & Length of the differential control volume & {$[\mathrm{m}]$} \\
\hline Exp & Experimental & \\
\hline $\mathrm{g}$ & Gravitational acceleration & {$\left[\mathrm{m} \cdot \mathrm{s}^{-2}\right]$} \\
\hline $\mathrm{h}$ & Heat transfer coefficient & {$\left[\mathrm{W} \cdot \mathrm{m}^{-2} \cdot \mathrm{K}^{-1}\right]$} \\
\hline $\mathrm{H}$ & Specific Enthalpy & {$\left[\mathrm{J}^{\mathrm{kg}} \mathrm{kg}^{-1}\right]$} \\
\hline$\widetilde{H}$ & Partial enthalpy & {$\left[\mathrm{J} . \mathrm{kg}^{-1}\right]$} \\
\hline $\mathrm{K}$ & Mass transfer coefficient & {$\left[\mathrm{m} \cdot \mathrm{s}^{-1}\right]$} \\
\hline$\lambda$ & Thermal conductivity & {$\left[\mathrm{W} \cdot \mathrm{m}^{-1} \cdot \mathrm{K}^{-1}\right]$} \\
\hline $\mathrm{L}$ & Length of the absorber & {$[\mathrm{m}]$} \\
\hline$\mu$ & Dynamic viscosity & {$\left[\mathrm{kg} \cdot \mathrm{m}^{-1} \cdot \mathrm{s}^{-1}\right]$} \\
\hline$\dot{m}$ & Mass flow rate & {$\left[\mathrm{kg} \cdot \mathrm{s}^{-1}\right]$} \\
\hline$\dot{m}_{N H 3}$ & Mass flow rate of the ammonia absorbed or desorbed at the film/vapour interface & {$\left[\mathrm{kg} \cdot \mathrm{m}^{-2} \cdot \mathrm{s}^{-1}\right]$} \\
\hline$\dot{m}_{\mathrm{H} 2 \mathrm{O}}$ & Mass flow rate of the water absorbed or desorbed at the film/vapourinterface & {$\left[\mathrm{kg} \cdot \mathrm{m}^{-2} \cdot \mathrm{s}^{-1}\right]$} \\
\hline$\eta$ & Mass effectiveness & {$[-]$} \\
\hline $\mathrm{N}_{\mathrm{NH} 3}$ & Surface mass flow rate of the ammonia absorbed or desorbed at the film/vapour interface & {$\left[\mathrm{kg} \cdot \mathrm{m}^{-2} \cdot \mathrm{s}^{-1}\right]$} \\
\hline $\mathrm{N}_{\mathrm{H} 2 \mathrm{O}}$ & Surface mass flow rate of the water absorbed or desorbed at the interface & {$\left[\mathrm{kg} \cdot \mathrm{m}^{-2} \cdot \mathrm{s}^{-1}\right]$} \\
\hline $\mathrm{Np}$ & Number of plates & \\
\hline Num & Numerical & \\
\hline
\end{tabular}




\begin{tabular}{|lll|}
\hline P & Pressure & {$[\mathrm{Pa}]$} \\
$\mathrm{Q}$ & Heat flux & {$[\mathrm{W}]$} \\
$\rho$ & Density & {$\left[\mathrm{kg} \cdot \mathrm{m}^{-3}\right]$} \\
$\mathrm{T}$ & Temperature & {$[\mathrm{K}]$} \\
th & Plate thickness & {$[\mathrm{m}]$} \\
$\mathrm{U}$ & Global heat transfer coefficient & {$\left[\mathrm{W} \cdot \mathrm{m}^{-2} \cdot \mathrm{K}^{-1}\right]$} \\
$\mathrm{x}$ & Mass fraction of ammonia in the liquid phase & {$[-]$} \\
y & Mass fraction of ammonia in the vapour phase & {$[-]$} \\
z & Mass fraction of ammonia in the absorbed or desorbed flow & {$[-]$} \\
& & \\
Subscripts & \\
& & \\
abs & Absorber,Absorbed, Absorption & \\
L & Liquid & \\
C & Coolant fluid & \\
cond & Condenser & \\
E & Evaporator & \\
film & Falling film & \\
G & Generator & \\
in & Inlet & \\
int & Film/Vapour interface & \\
max & Maximum & \\
out & Outlet & \\
P & Plate & \\
rect & Rectification exchanger & \\
Ref & Reference & \\
SEN & Sensible liquid & \\
SEN & Sensible vapour & \\
SP & Poor solution & \\
SR & Rich solution & \\
sat & Saturated solution & \\
V & Vapour & \\
VC & Condensate & \\
\hline & & \\
\hline
\end{tabular}

\section{Experimental device description}

The experimental study was performed on a single effect ammonia-water absorption chiller prototype of $5 \mathrm{~kW}$ (Fig. 1) designed for solar applications [25]. The prototype of the chiller is composed of 7 plate heat exchangers. The four main heat exchangers are the generator, the absorber, the evaporator, and the condenser. The otheronesrequired to the proper functioning of the cycle are a solution heat exchanger located between rich and poor solution, a subcooler located between the liquid refrigerant at the inlet of the evaporator and the vapour refrigerant at the outlet of the evaporator and a rectification exchanger (Fig. 2).

The system includes four tanks (T1, T2, T3 and T4) used as liquid-vapour splitters (T2 and T3), as solution storage (T1) and as refrigerant storage (T4). A volumetric pump is used to transfer solution from absorber to generator. To control the chiller, a refrigerant expansion valve adjusts superheating at the outlet of the evaporator and a solution expansion valve adjusts the liquid level in the solution storage tank at the outlet of the absorber. 




Fig. 1. Picture of the prototype of ammonia-water absorption chiller



Fig. 2. Architecture of the absorption chiller

The cooling effect is generated, as in vapour compression chillers, by the evaporation of a refrigerant fluid $\left(\mathrm{NH}_{3}\right)$ exchanging heat with the cold source $\left(\mathrm{Q}_{\mathrm{E}}\right)$. In the driving part of the absorption chiller (absorber, generator and rectification exchanger) a physicochemical process replaces the mechanical process of the vapour compression system by using thermal energy rather than mechanical work.

The working principle of this driving part is as follows: the ammonia vapour from the evaporator is absorbed by mass diffusion at low pressure in the absorbent poor solution inside the absorber. During the exothermic absorption process, a quantity of heat $\left(\mathrm{Q}_{\mathrm{C}, \mathrm{abs}}\right)$ is released to a cooling fluid (water). The rich solution at the outlet of the absorber is pumped at low pressure and is preheated in the solution heat exchanger before being injected in the generator. The endothermic desorption process releases ammonia vapour by addition of a quantity of heat $\left(\mathrm{Q}_{\mathrm{G}}\right)$ and a poor solution leaves the generator. The poor solution is cooled, depressurized in the solution expansion valve and re-injected in the absorber. The ammonia vapour produced by the generator is injected in the rectification exchanger to remove some water traces by partial condensation of the refrigerant with external cooling.

The refrigerant is thus injected in the refrigerating part of the chiller. First, in the condenser at high pressure where the vapour is condensed releasing a quantity of heat $\left(\mathrm{Q}_{\mathrm{C}, \mathrm{cond}}\right)$ to the cooling fluid (water). And then the liquid refrigerant at the outlet of the condenser return to the evaporator through the subcooler and the expansion valve to generate the cooling effect.

Industrial plate heat exchangers are implemented and the conception of the chiller is made by using only standard components with the aim of reducing future final costs and specific developments. Ammonia being a very corrosive fluid, especially with water, a close attention was paid to all materials in contact with the fluid, using as far as possible stainless steel and EPDM or PTFE for seals and membranes. 


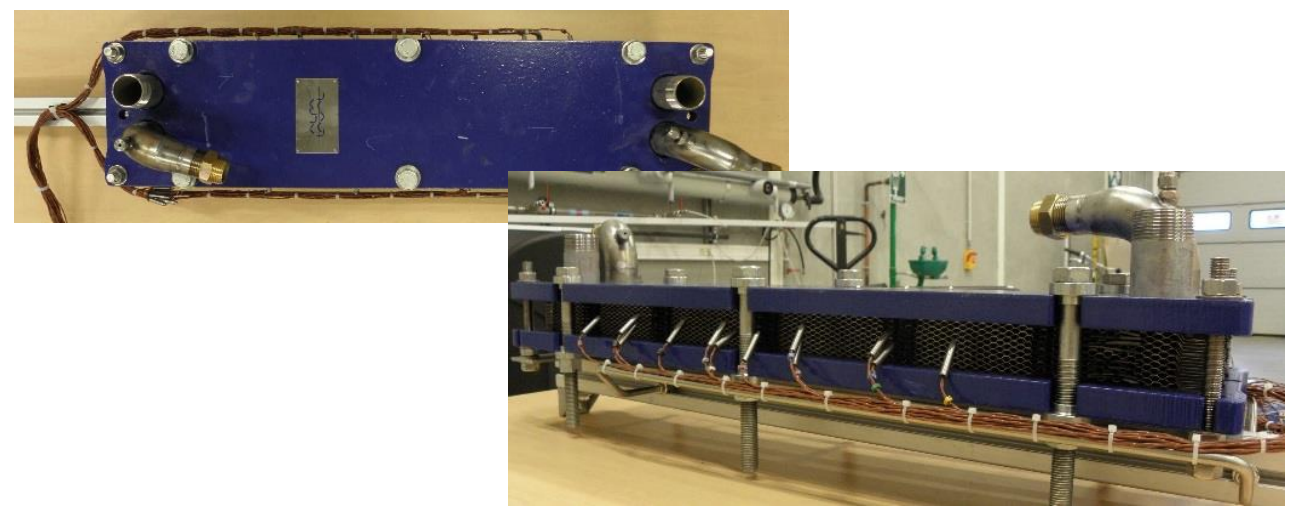

Fig. 3. Picture of the gasketedplate-and-frame absorber.

The absorber analysed in this study (Fig. 3) is a gasketed plate-and-frame commercial heat exchanger with corrugated plates.

It is a falling film absorber. The ammonia-water poor solution and the refrigerant vapour enter at the top of the absorber. The poor solution flows in the form of falling film and refrigerant vapour flows in the same direction as the solution (from the top to the bottom). The coolant fluid enters at the bottom of the absorber and cools the absorption process by flowing counter-current with the falling film. The vapour refrigerant is absorbed by the falling film along the absorber and an ammonia-water rich solution leaves at the bottom of the absorber (Fig. 4).

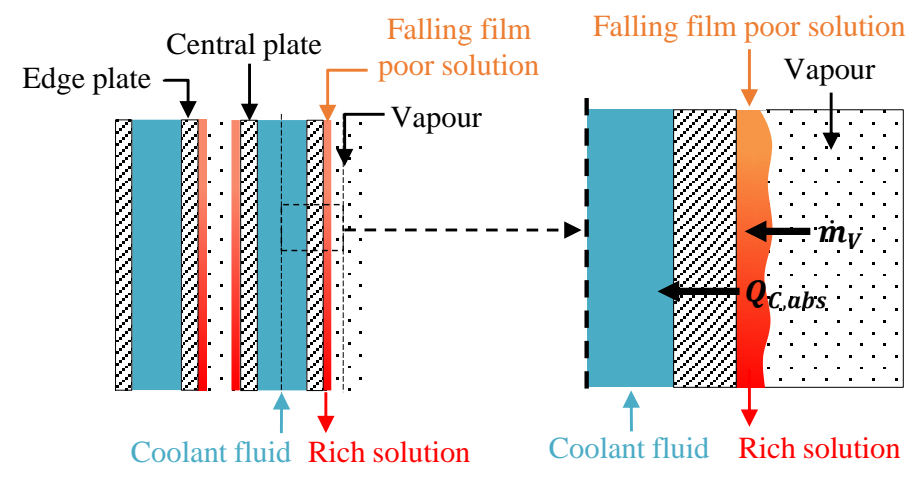

Fig. 4. Schematic representation of the plate falling film absorber.

The absorber is composed of 16 plates: 8 channels are supplied with coolant fluid and 7 channels are supplied with liquid solution and vapour. Therefore, 14 falling films are available. Twelve plates are considered as central plates (because they are at the centre of the absorber: one coolant fluid channel cools two falling films) and two plates are considered as edge plates (one coolant fluid channel cools one falling film) (Fig. 4). Geometric dimensions and materials of the absorber are summarized in Table 1 .

Table 1. Geometric dimensions of gasketed plate-and-frame heat exchanger.

\begin{tabular}{ll}
\hline Number of plates & 16 \\
Plate type & Corrugated plates \\
Plate material & Alloy 316 \\
Plate width & $96 \mathrm{~mm}$ \\
Plate length & $668 \mathrm{~mm}$ \\
Plate thickness & $0.5 \mathrm{~mm}$ \\
Corrugation height & $1.8 \mathrm{~mm}$ \\
Corrugation angle & $35^{\circ}$ \\
\hline
\end{tabular}


The ammonia-water absorption chiller is fully instrumented (Fig. 2). Measures of temperature(with T-type thermocouples for working fluid and with Platinum resistance thermometer for heat transfer fluid), density and mass flow rate (with Coriolis flow meters)and pressure are available at the inlet and the outlet of the main components. Thanks to this instrumentation, it is possible to calculate the ammonia mass fraction of the absorber's inlet and outlet flows (poor solution, rich solution and vapour). Instruments also enable to know the coolant temperature and mass flow rate at the bounds of the absorber. The chiller sensors are quantified and described in Table 2. Uncertaintieswas calculated considering the totality of the measurement sequence.

Table 2. Sensors number and measurement characteristics.

\begin{tabular}{lll}
\hline Sensors type & Number & Uncertainty (+/-) \\
\hline Cooling or heating fluid temperature (Pt) & 10 & $0.15 \mathrm{~K}$ \\
Refrigerant and solution temperature (TC) & 15 & $0.18 \mathrm{~K}$ \\
Pressure (0-10bar) & 2 & $0.4 \%$ \\
Pressure (0-20 bar) & 2 & $0.8 \%$ \\
Coriolis flow meters: & 3 & $0.3 \%$ \\
$-\quad$ Mass flow rate & 1 & $2.3 \mathrm{~kg} / \mathrm{m}^{3}$ \\
$-\quad$ Density & $1 \%$ \\
Electromagnetic flowmeter: $\dot{m}_{C, a b s} \quad$ Pt: Platinum resistance thermometer, TC: Thermocouple
\end{tabular}

In addition to this instrumentation, the absorber is locally instrumented (Fig. 5). Indeed, 24 T-type thermocouples with a diameter of 0.5 mmwere put inside the coolant fluid channels of the absorber to study in more detail the absorption process. Seals were drilled with a needle to insert the sensors. Because of the danger of leak which is not negligible, channels supplied with ammonia were not instrumented. Only four channels of coolant fluid were instrumented.

This instrumentation enablesto know the coolant fluid temperature along a central plate (10 measures), the coolant fluid temperature ( 6 measures) and the wall temperature ( 5 measures) along another central plate and to have three temperature measures on edge plates. The uncertainty of these temperature sensors is $+/-0.19 \mathrm{~K}$. Some measurements are duplicatedfor more accuracy.

The temperature sensors are maintained with glue to measure the coolant fluid temperature inside the channel and with glue and metal adhesive to measure the plate temperature. Measurements of thermal conductivity of the metal adhesive werecarried out to estimate the thermal resistance due to the glue which can modify and skew plate temperature measurements.



Fig. 5. Picture of an instrumented central plate of the gasketed plate-and-frame absorber.

External fluid temperatures, rich solution and external mass flow rates are the only control parameters available. They are used to modify the operating conditions of the chiller in order to perform the sensibility analysis of the absorber. 


\section{Experimental results}

Experimental tests wereperformed on the absorber with several operating conditions $\left(352.3 \mathrm{~K} \leq \mathrm{T}_{\mathrm{G}, \mathrm{in}} \leq 387.2 \mathrm{~K} ; 280.9 \mathrm{~K}\right.$ $\left.\leq \mathrm{T}_{\mathrm{E}, \mathrm{in}} \leq 291.0 \mathrm{~K} ; 295.3 \mathrm{~K} \leq \mathrm{T}_{\mathrm{C}, \mathrm{n}} \leq 311.4 \mathrm{~K} ; 0.012 \mathrm{~kg} / \mathrm{s} \leq \dot{\mathrm{m}}_{\mathrm{SR}} \leq 0.0375 \mathrm{~kg} / \mathrm{s} ; 0.06 \mathrm{~kg} / \mathrm{s} \leq \dot{\mathrm{m}}_{\mathrm{C}, \mathrm{abs}} \leq 0.454 \mathrm{~kg} / \mathrm{s}\right)$ to analyse its behaviour. In this paper, the study focuses on the impact of the coolant fluid mass flow rate on the absorber performances.

Two performance criteria were analysed:

- the absorbed mass flow rate $\left(\dot{m}_{a b s}\right)$ which is the vapour mass flow rate at the inlet of the absorber;

- the mass effectiveness $\left(\eta_{a b s}\right)$ defined as the ratio between the absorbed mass flow rate and the maximum absorbed vapour mass flow rate considering an infinite counter flow absorber:

$$
\eta_{a b s}=\frac{\dot{m}_{a b s}}{\dot{m}_{a b s_{\max }}}
$$

Global mass and species balances in the absorber lead to the calculation of the mass effectiveness as a function of the rich solution ammonia mass fraction, the poor solution ammonia mass fraction, the vapour ammonia mass fraction and the saturated rich solution ammonia mass fraction:

$$
\eta_{a b s}=\frac{\frac{\left(x_{S R}-x_{S P}\right)}{\left(y_{V}-x_{S R}\right)}}{\frac{\left(x_{S R, s a t}-x_{S P}\right)}{\left(y_{V}-x_{S R, s a t}\right)}}
$$

The saturated rich solution ammonia mass fraction $\left(x_{S R, s a t}\right)$, is calculated for a counter flow absorber with an infinite length. In this work, the coolant fluid mass flow rate is adjusted to make the falling film solution being always the heat transfer limiting fluid. Therefore, in an infinite absorber the outlet solution temperature would be equal to the inlet coolant fluid temperature. Then, $x_{S R, S a t}$ has to be calculated at the inlet coolant fluid temperature.

The experimental device makes possible the analysis of absorbed mass flow rates and mass effectiveness thanks to temperature, pressure, mass flow rate and density measurements. Fig. 6. shows the variation of the mass effectiveness and the absorbed mass flow rate as a function of the coolant mass flow rate. Both parameters increase with the coolant mass flow rate, the absorption process being more efficient.

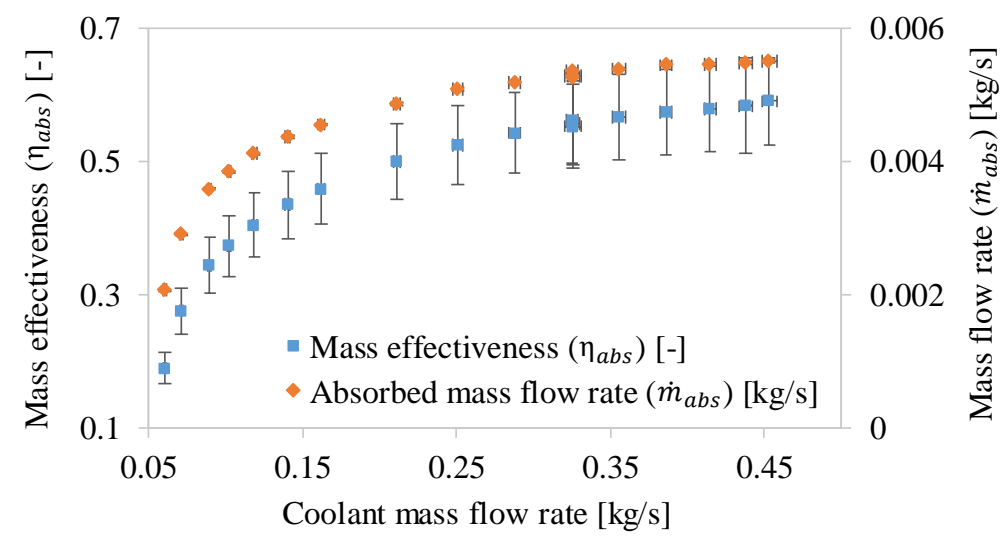

Fig. 6. Mass effectiveness and absorbed mass flow rate versus coolant mass flow rate.

This more efficient absorption process has an impact on the global machine behaviour and on the characteristics of the absorber inlet flows. Fig 7 illustrates this impact for three characteristics of poor solution at the inlet of the absorber: temperature (a), ammonia mass fraction (b) and mass flow rate (c) decrease when the coolant mass flow rate increases. The temperature decreases because the cooling of the absorption process is better: the rich solution temperature at the outlet of the absorber decreases and the cooling of the poor solution in the solution heat exchanger is then more effective. The poor solution mass flow rate reduces because the absorbed mass flow rate increases and the rich solution mass flow rate remains steady during these tests.

The coolant mass flow rate raisealso implies the increase of the vapour temperature, the vapour ammonia mass fraction and the vapour mass flow rate, the increase of the high pressure and the decrease of the low pressure. 




Coolant mass flow rate $[\mathrm{kg} / \mathrm{s}]$

a)

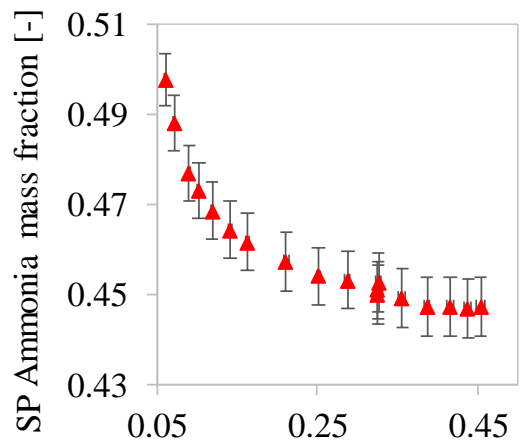

Coolant mass flow rate $[\mathrm{kg} / \mathrm{s}]$

b)

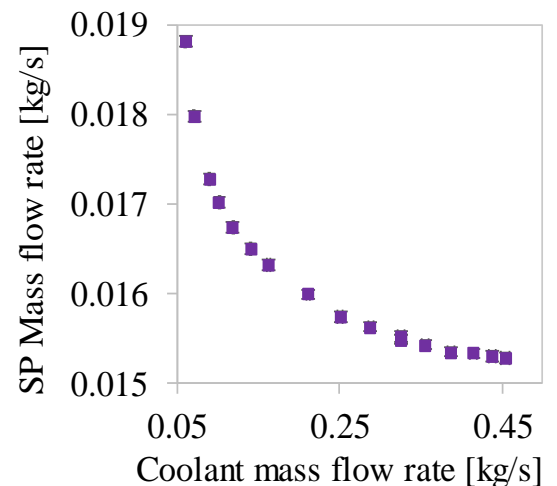

c)

Fig. 7. a) Poor solution temperature versus coolant mass flow rate. b) Poor solution ammonia mass fraction versus coolant mass flow rate. c) Poor solution mass flow rate versus coolant mass flow rate.

This prototype being a real chiller, all parameters are combined. The variation of the chiller control parameters has simultaneous impacts on temperature, ammonia mass fraction, mass flow rate and pressure of the poor solution and the vapour at the inlet of the absorber.

These impacts have retroactive effects on the absorption mass effectiveness and the absorbed mass flow rate. Indeed, the reduction of poor solution temperature and ammonia mass fraction implies an increase of the absorption capacity whereas the poor solution mass flow rate reduction implies a decrease of the absorption potential.

So, the increase of the absorber performances is partially causedbythe increase of the coolant mass flow rate.

Therefore, it is challengingto experimentally analyse the results and to dissociate the coolant mass flow rate impact on the absorber performances. Anumerical study is thus required to perform a detailed and exhaustive study of the coupled heat and mass transfer in the falling film absorber.

\section{Numerical model description}

A one dimension numerical model of the absorber was developed in order to complete the experimental investigation and to perform the detailed study of combined heat and mass transfers in the falling film plate absorber.

The mathematical model is based on mass balances, species balances, enthalpy balances, mass and heat transfer equations and equilibrium conditions at the vapour/solution interface for each control volume of the absorber (Fig. 8) [12]. Mass transfer resistances in both liquid and vapour phases are considered because water is a volatile absorbent existingin the two phases. Transport phenomena are thus more complex compared with other currently used working pair as water and lithium bromide (a non-volatile absorbent) [23]. Heat and mass transfer coefficients are calculated using empirical correlations.

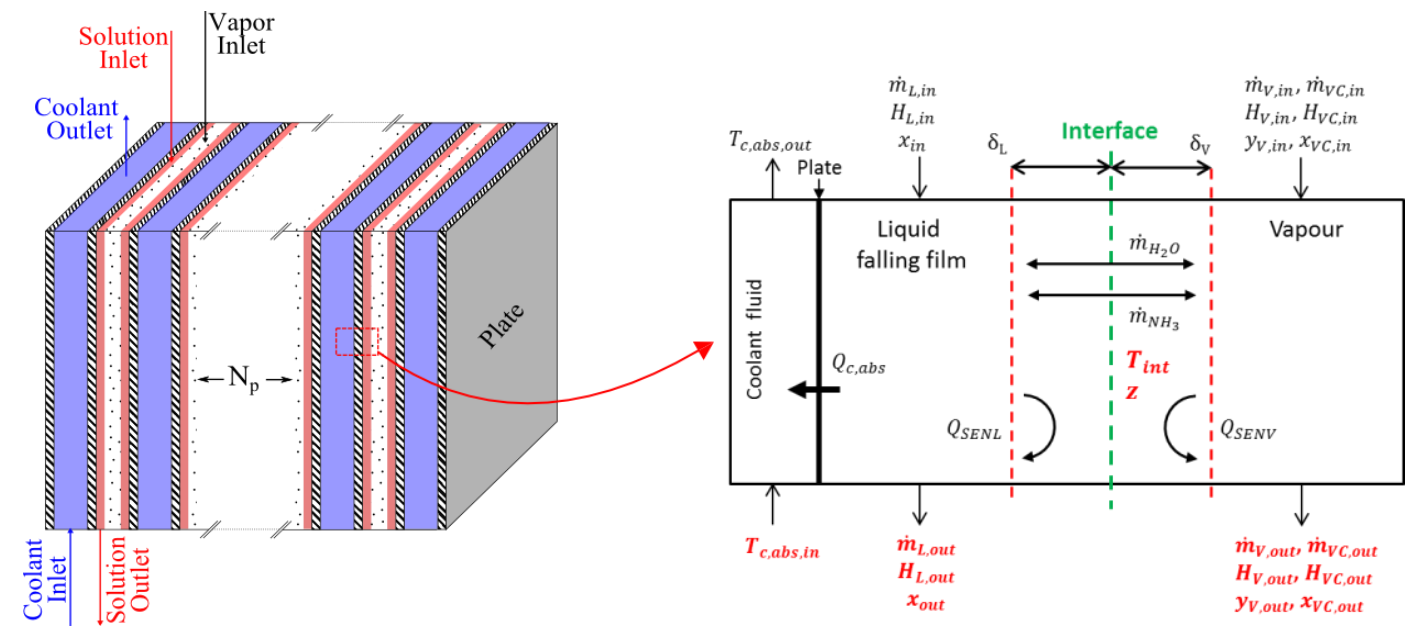

Fig. 8. Diagram of the absorber (left), Differential control volume of the absorber (right).

This model is based on the following assumptions:

- Pressure is homogenous in the absorber (vapour pressure drop supposed negligible);

- Solution at the vapour/solution interface is supposedto be saturated; 
- Absorption process is assumed to be in steady state;

- The plates of the heat exchanger are assumed to be flat plates;

- Exchange surface is totally wet (there is no direct exchange between the vapour phase and the plate);

- No heat exchange with the environment through the absorber walls is considered;

- The temperatures of liquid phase and vapour phase in each control volume are assumed to be mixing temperatures;

- Liquid falling films are laminar;

- Flow rates distribution is equal in all channels of the absorber;

- Effect of non-absorbable gases is ignored;

- Longitudinal conduction inside the plates and inside the fluids is negligible;

- Vapour is saturated at the entrance of the absorber;

- A part of the vapour condenses along the absorber leading to droplets apparition.

As experimentally observed, the refrigerant which comes from the evaporator and the subcooleris in a two-phase flow configuration with a small part of liquid. Before the inlet of the absorber, the refrigerant and the poor solution are mixed in order to transferthe refrigerant liquid part to the liquid poor solution comingfrom the generator. So, vapour at the input of the absorber is saturated. During the absorption process, the vapour ammonia mass fraction greatly decreases and the vapour temperature increases. The vapour phase can enter in the two-phase domain. Therefore, a partof this vapour can condense along the absorber leading to droplets formation. These droplets are supposed to stayin the vapour phase (V) because the interface temperature being warmer, droplets vaporise again close to the interface. In this paper, the liquid part inside the vapour phase is called the condensed vapour phase (VC), andis in equilibrium with vapour phase. At the outlet of the absorber, the condensed vapour phase is mixed with the liquid phase (L). Main model equations are presented in the following section.

Mass balances, in the vapour phase (3) and in the liquid phase (4) are:

$$
\begin{gathered}
\dot{m}_{V, \text { in }}+\dot{m}_{V C, \text { in }}-\dot{m}_{V, \text { out }}-\dot{m}_{V C, \text { out }}-\left(\dot{m}_{N H 3}+\dot{m}_{H 2 O}\right)=0 \\
\dot{m}_{L, \text { in }}-\dot{m}_{L, \text { out }}+\dot{m}_{N H 3}+\dot{m}_{H 2 O}=0
\end{gathered}
$$

Species balances, in the vapour phase (5) and in the liquid phase (6) are:

$$
\begin{gathered}
\dot{m}_{V, \text { in }} \cdot y_{V, \text { in }}+\dot{m}_{V C, \text { in }} \cdot x_{V C, \text { in }}-\dot{m}_{V, \text { out }} \cdot y_{V, \text { out }}-\dot{m}_{V C, \text { out }} \cdot x_{V C, \text { out }}-\dot{m}_{N H 3}=0 \\
\dot{m}_{L, \text { in }} \cdot x_{\text {in }}-\dot{m}_{L, \text { out }} \cdot x_{\text {out }}+\dot{m}_{N H 3}=0
\end{gathered}
$$

$\dot{m}_{N H 3}$ and $\dot{m}_{H 2 O}$ are the mass fluxes of ammonia and water absorbed or desorbed at the interface between liquid and vapour phases. Positive values imply a mass transfer from vapour to liquid (absorption) and negative values imply a mass transfer from liquid to vapour (desorption).

Energy balance in the vapour phase (7) is:

$$
\begin{aligned}
-Q_{S E N_{V}}+\dot{m}_{V, \text { in }} . & H_{V, \text { in }}\left(T_{V, \text { in }}, P, y_{V, \text { in }}\right)+\dot{m}_{V C, \text { in }} \cdot H_{V C, \text { in }}\left(T_{V C, \text { in }}, P, x_{V C, \text { in }}\right) \\
& -\dot{m}_{V, \text { out }} \cdot H_{V, \text { out }}\left(T_{V, \text { out }}, P, y_{V, \text { out }}\right)-\dot{m}_{V C, \text { out }} \cdot H_{V C, \text { out }}\left(T_{V C, \text { out }}, P, x_{V C, \text { out }}\right) \\
& -\dot{m}_{N H 3} . \widetilde{H}_{V, N H 3}\left(T_{\text {int }}, P\right)-\dot{m}_{H 2 O} . \widetilde{H}_{V, H 2 O}\left(T_{\text {int }}, P\right)=0
\end{aligned}
$$

The ammonia-water mixed vapour is considered as a perfect ideal gas mixture, so partials enthalpies $\left(\widetilde{H}_{V, N H 3}\right.$ and $\left.\widetilde{H}_{V, H 2 O}\right)$ are equal to pure component enthalpies $\left(H_{V, N H 3}\right.$ and $\left.H_{V, H 2 O}\right)$.

Energy balance in the liquid phase is (8):

$$
\begin{gathered}
-Q_{S E N_{L}}-Q_{C}+\dot{m}_{L, \text { in }} \cdot H_{L, \text { in }}\left(T_{L, \text { in }}, P, x_{\text {in }}\right)-\dot{m}_{L, \text { out }} . H_{L, \text { out }}\left(T_{L, \text { out }}, P, x_{\text {out }}\right)+\dot{m}_{N H 3} \cdot \widetilde{H}_{L, N H 3}\left(T_{\text {int }}, P\right) \\
+\dot{m}_{H 2 O} \cdot \widetilde{H}_{L, H 2 O}\left(T_{\text {int }}, P\right)=0
\end{gathered}
$$

$\widetilde{H}_{L, N H 3}$ and $\widetilde{H}_{L, H 2 O}$ are partial enthalpies of ammonia and water in the liquid phase.

The solution at the vapour/solution interface is assumed to be saturated; therefore, the equilibrium mass fractions of ammonia at the interface $\left(x_{i n t}\right.$ and $\left.y_{\text {int }}\right)$ can be expressed by saturation equations.

Energy balance at the interface between liquid and vapour phases (9) is: 


$$
\begin{gathered}
\dot{m}_{N H 3} \cdot\left(H_{V, N H 3}\left(T_{N H 3, V}, P\right)-\widetilde{H}_{L, N H 3}\left(T_{N H 3, L}, P\right)\right)+\dot{m}_{H 2 O} \cdot\left(H_{V, H 2 O}\left(T_{H 2 O, V}, P\right)-\widetilde{H}_{L, H 2 O}\left(T_{H 2 O, L}, P\right)\right) \\
+Q_{S E N_{L}}+Q_{S E N_{V}}=0
\end{gathered}
$$

$Q_{S E N V}$ is the sensible heat exchanged between the vapour phase and the interface and $Q_{S E N L}$ is the sensible heat exchanged between the liquid phase and the interface.

When heat and mass transfers are coupled at the interface of a liquid phase and a vapour phase, an additional quantity of heat is transferred due to the heat capacity of mass transfer. So, $Q_{S E N V}(10)$ and $Q_{S E N L}(11)$ are expressed by [26, 27]:

$$
\begin{aligned}
& Q_{S E N_{V}}=\frac{c_{V}}{1-e^{-c_{V}}} \cdot h_{V} \cdot d A i \cdot\left(T_{V}-T_{i n t}\right) \\
& Q_{S E N_{L}}=\frac{c_{L}}{1-e^{-c_{L}}} \cdot h_{L} \cdot d A i \cdot\left(T_{L}-T_{i n t}\right)
\end{aligned}
$$

With:

$$
\begin{gathered}
c_{V}=\frac{N_{N H 3} \cdot C p_{V, N H 3}+N_{H 2 O} \cdot C p_{V, H 2 O}}{h_{V}} \\
c_{L}=\frac{N_{N H 3} \cdot C p_{L, N H 3}+N_{H 2 O} \cdot C p_{L, H 2 O}}{h_{L}}
\end{gathered}
$$

$N_{N H 3}$ and $N_{H 2 O}$ are the surface mass fluxes of ammonia or water absorbed or desorbed at the interface between liquid and vapour phases.

Mass diffusion and bulk transport of ammonia and water across the liquid-vapour interface involve mass transfer between the liquid and the vapour phase $[15,26]$.

The total surface mass flux which is transferred between vapour and liquid-vapour interface is expressed by (14):

$$
N_{N H 3}+N_{H 2 O}=K_{V} \cdot \rho_{V} \cdot \ln \left(\frac{z-y_{\text {int }}}{z-y}\right)
$$

The total surface mass flux which is transferred between liquid-vapour interface and liquid phase is expressed by (15):

$$
N_{N H 3}+N_{H 2 O}=K_{L} \cdot \rho_{L} \cdot \ln \left(\frac{z-x}{z-x_{\text {int }}}\right)
$$

$\mathrm{z}$ is the mass fraction of ammonia in the absorbed/desorbed flux. It is expressed as follows (16):

$$
z=\frac{N_{N H 3}}{N_{N H 3}+N_{H 2 O}}
$$

The liquid mass transfer coefficient $K_{L}$ is calculated with an empirical correlation developed by Yih and Chen [28]. This correlation is only valid in a falling film with a Reynolds number between 49 and 300 and in fully developed conditions. The vapour heat transfer coefficient $h_{V}$ is calculated with an empirical correlation developed by Kakaç and al [29]. It is based on laminar flow conditions inside a parallel plate channel, the surface temperature is assumed to be uniform and edge effects due to finite width of parallel plate channel are neglected $[15,30]$. The correlation is only valid for a Reynolds number value under 2200 and in fully developed conditions. The vapour mass transfer coefficient $K_{V}$ and the liquid heat transfer coefficient $h_{L}$ are determined by the Chilton and Colburn analogy [31].

To evacuate the heat of the absorption process, the coolant fluid absorbs an amount of heat which is calculated with an energy balance in the coolant fluid (17):

$$
d Q_{C, a b s}+\dot{m}_{C, a b s} \cdot\left(H_{C, a b s, i n}-H_{C, a b s, o u t}\right)=0
$$

With:

$$
d Q_{C, a b s}=U \cdot d A i \cdot\left(T_{L}-T_{C, a b s}\right)
$$

And:

$$
\frac{1}{U}=\frac{1}{h_{C}}+\frac{t h}{\lambda_{P}}+\frac{1}{h_{\text {film }}}
$$

$T_{L}$ is the falling film temperature and $U$ is the global heat transfer coefficient. This coefficient both considers convective transfers (between falling film, coolant fluid and plate) and conduction across the absorber plate. 
$h_{C}$, coolant side heat transfer coefficient, is calculated with a correlation developed for corrugated plates with a Reynolds number value between 50 and 14600 [32]. $h_{\text {film }}$, the convective heat transfer coefficient between the falling film and the cooling plates, is calculated with the Wilke's correlation based on experimental measurementsand is only valid for a Reynolds number value below $\operatorname{Re}=2460 . \mathrm{Pr}^{-0.646}(\mathrm{Pr}$ beingthe Prandtl number) and in fully developed conditions [33].This correlation was originally developed for smooth vertical tubes while the present study was achieved on vertical plates. The tube curvature effect on the falling film is considered negligible. . That assumption make possible the use of the Wilke's correlation for flat plate.

The Reynolds and Prandtl numbers associated with the falling film, the vapour and the coolant were calculated, and flow regimes were determined in order to validate the choice of correlations. Table 3 summarizes all these values and the flow regimes:

\begin{tabular}{|c|c|c|c|}
\hline & $\operatorname{Re}[-]$ & $\operatorname{Pr}[-]$ & Flow regime \\
\hline Falling film & $50<\operatorname{Re}<170$ & $4.8<\operatorname{Pr}<7.3$ & laminar \\
\hline Vapour & $20<\operatorname{Re}<1800$ & $1.0<\operatorname{Pr}<1.1$ & laminar \\
\hline Coolant & $620<\operatorname{Re}<2700$ & $4.5<\operatorname{Pr}<6.6$ & turbulent \\
\hline
\end{tabular}

The thickness of the falling film was calculatedbetween 0.15 and $0.17 \mathrm{~mm}$. It is expressed as follows [27]:

$$
\delta=\left(\frac{3 \cdot \mu_{L} \cdot \Gamma_{L}}{\rho^{2} \cdot g}\right)^{\frac{1}{3}}
$$

In this study, thermodynamic properties are calculated with the NIST REFPROP softwarewhich enables the calculation of several fluids and mixtures properties and more particularly ammonia-water mixture properties [34]. Transport properties are predicted using Conde Engineering correlations [35].

A simulation tool was created with the Scilab software. The implemented numerical method providesan iterative resolution of nonlinear equations in each differential control volume of the absorber (Fig. 8). With this simulation tool, local analysis of combined heat and mass transfers through the liquid/vapour interface can be performed to study the absorption process along the absorber plate.

To compare numerical results with experimental measurements, the simulations wereseparately performed for the central plates and for the edge ones(Fig. 4). These two numerical simulations make possible the calculation of mass flow rates, concentration and temperature using masses, species and energies balances at the absorber outlet mixing point.

As a result, the numerical model provides thermodynamic properties ( $\mathrm{T}, \mathrm{P}, \dot{m}, \mathrm{H}, \mathrm{x}, \mathrm{y})$ and transport properties along the absorber plate. It is thus possible to analyse heat and mass flows through the liquid vapour interface. This methodfacilitatesthe study of the absorption process and the analysis of the absorber behaviour to predict and enhance its performances.

\section{Experimental global validation}

Tests carried out on the absorber with several operating conditions lead to a specific analyse of the absorber with variation of its inlets flow conditions. These experimental test conditions were used as input data to perform numerical simulations in order to carry out a comparison between numerical and experimental results. The operating conditions of the 10 experiments considered for this study are listed in Table 4. Table 5 summarizes results obtained experimentally and numerically.

Table 4. Operating conditions at the inlet of the absorber

\begin{tabular}{cccccccccc}
\hline Tests & $\dot{m}_{V, \text { in }}[\mathrm{kg} / \mathrm{s}]$ & $\dot{m}_{L, \text { in }}[\mathrm{kg} / \mathrm{s}]$ & $T_{V, \text { in }}[\mathrm{K}]$ & $T_{L, \text { in }}[\mathrm{K}]$ & $x_{\text {in }}[-]$ & $y_{\text {in }}[-]$ & $P[\mathrm{~Pa}]$ & $T_{C, a b s, \text { in }}[\mathrm{K}]$ & $\dot{m}_{C, a b s}[\mathrm{~kg} / \mathrm{s}]$ \\
\hline 1 & 0.00513 & 0.0157 & 298.6 & 312.2 & 0.4578 & 0.9976 & $6.07 .10^{5}$ & 300.1 & 0.330 \\
2 & 0.00383 & 0.0170 & 297.9 & 317.4 & 0.4885 & 0.9954 & $6.29 .10^{5}$ & 304.1 & 0.330 \\
3 & 0.00608 & 0.0147 & 298.4 & 309.2 & 0.4331 & 0.9985 & $5.98 .10^{5}$ & 297.1 & 0.331 \\
4 & 0.00441 & 0.0165 & 298.3 & 310.3 & 0.5002 & 0.9983 & $6.21 .10^{5}$ & 300.2 & 0.324 \\
5 & 0.00458 & 0.0163 & 298.3 & 313.7 & 0.4626 & 0.9967 & $5.78 .10^{5}$ & 300.2 & 0.324 \\
6 & 0.00552 & 0.0237 & 294.7 & 315.6 & 0.4905 & 0.9918 & $6.03 .10^{5}$ & 300.1 & 0.332 \\
7 & 0.00553 & 0.0265 & 293.7 & 317.4 & 0.4980 & 0.9912 & $6.04 .10^{5}$ & 300.1 & 0.332 \\
8 & 0.00384 & 0.0170 & 296.5 & 318.5 & 0.4731 & 0.9976 & $6.29 .10^{5}$ & 300.1 & 0.102 \\
9 & 0.00548 & 0.0153 & 300.8 & 311.4 & 0.4470 & 0.9991 & $6.09 .10^{5}$ & 300.3 & 0.438 \\
10 & 0.00521 & 0.0156 & 295.1 & 312.5 & 0.4522 & 0.9933 & $6.03 .10^{5}$ & 300.2 & 0.327 \\
\hline
\end{tabular}

Table 5. Comparison of experimental and numerical results at the outlet of the absorber 


\begin{tabular}{ccccccc}
\hline \multirow{2}{*}{ Tests } & \multicolumn{2}{c}{$\eta_{a b s}[-]$} & \multicolumn{2}{c}{$\dot{m}_{V, a b s}[\mathrm{~kg} / \mathrm{s}]$} & \multicolumn{2}{c}{$Q_{C, a b s}[\mathrm{~kW}]$} \\
\cline { 2 - 6 } & Num & Exp & Num & Exp & Num & Exp \\
\hline 1 & 0.609 & 0.553 & 0.00566 & 0.00513 & 8.502 & 7.549 \\
2 & 0.621 & 0.584 & 0.00407 & 0.00383 & 6.426 & 5.871 \\
3 & 0.580 & 0.507 & 0.00695 & 0.00608 & 10.285 & 8.872 \\
4 & 0.591 & 0.541 & 0.00484 & 0.00441 & 7.139 & 6.400 \\
5 & 0.610 & 0.556 & 0.00502 & 0.00458 & 7.801 & 6.975 \\
6 & 0.478 & 0.473 & 0.00557 & 0.00552 & 8.922 & 8.437 \\
7 & 0.443 & 0.442 & 0.00554 & 0.00553 & 9.208 & 8.723 \\
8 & 0.377 & 0.373 & 0.00392 & 0.00384 & 6.416 & 5.991 \\
9 & 0.648 & 0.583 & 0.00610 & 0.00548 & 9.094 & 8.069 \\
10 & 0.603 & 0.554 & 0.00567 & 0.00521 & 8.504 & 7.536 \\
\hline
\end{tabular}

The test number 1 is the reference point $\left(\mathrm{T}_{\mathrm{G}, \mathrm{in}}=362.3 \mathrm{~K} ; \mathrm{T}_{\mathrm{E}, \mathrm{in}}=290.8 \mathrm{~K} ; \mathrm{T}_{\mathrm{C}, \text { in }}=300.1 \mathrm{~K} ; \dot{\mathrm{m}}_{\mathrm{SR}}=0.02083 \mathrm{~kg} / \mathrm{s} ; \dot{\mathrm{m}}_{\mathrm{C}, \mathrm{abs}}=0.03301 \mathrm{~kg} / \mathrm{s}\right)$ and these 10 tests showed experimental energy balances between $0 \%$ and $5 \%$. Fig. 9. presents numerical results versus experimental results:

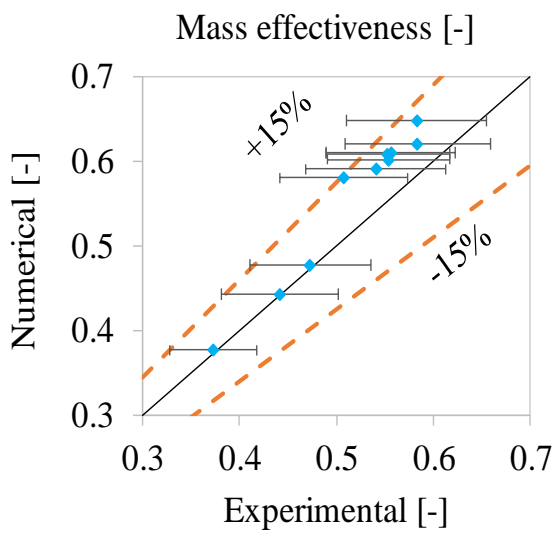

a)

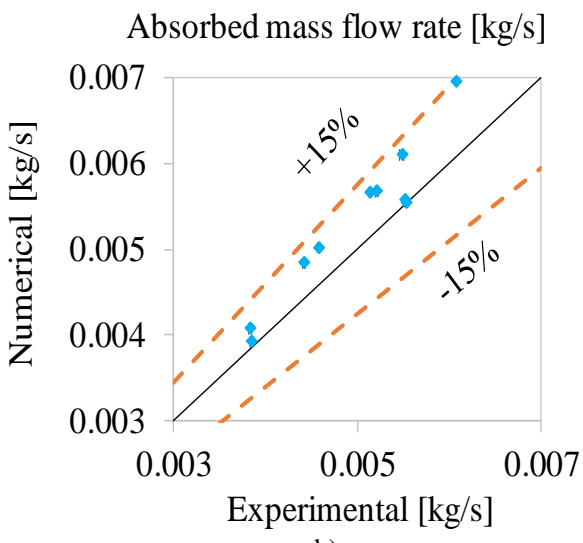

b)

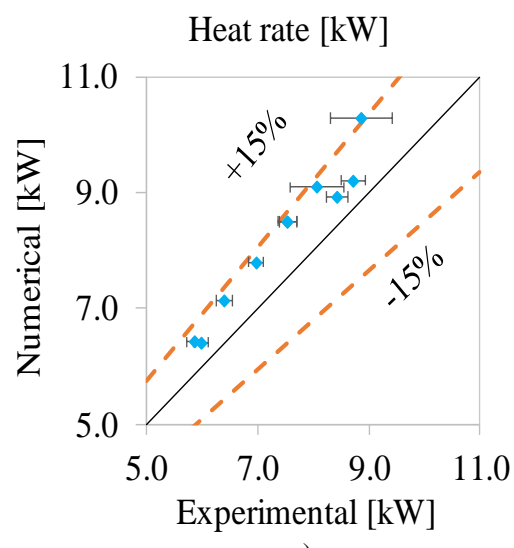

c)

Fig. 9. Numerical results versus experimental results: a) Mass effectiveness. b) Absorbed mass flow rate. c) Heat rate

Comparison between experimental and numerical results in terms of mass effectiveness, absorbed mass flow rate and heat rate shows a rather good agreement since a maximal relative differenceof $15 \%$ is observed. Regarding the mass effectiveness (Fig.9.a) and the absorbed mass flow rate (Fig.9.b), numerical results are superior to experimental ones, whichmeans that absorption process is overestimated in the numerical study. This more important absorption process implies an amount of heat absorbed in the coolant fluid higher in the numerical study than in the experimental one (Fig.9.c).

This overestimation could be explained by the inaccuracy of the assumption of totally wet exchange surface. Indeed, experimentally, dry areas arepossible because of a poor distribution of the liquid film. The assumption of flat plates also affects the wet exchange surface difference between numerical and experimental study. An additional research needs to be conducted to analysethe impact of these assumptions.

\section{Detailed analysis of numerical results}

As mentioned earlier, the developed numerical model provides temperature, mass flow and $\mathrm{NH}_{3}$ mass fraction profiles along the absorber. Mass fluxes of ammonia or water absorbed or desorbed can also be calculated. All mass, species and energy balances and heat and mass transfer equations are solved with residual errors lower than $1.10^{-7}$. The following section presentsthe profiles of the reference point in central channels and shows a detailed analysis of local phenomena.

Fig. 10. points out the variation of temperatures along the absorber. The heat transfer fluid cools the absorption process by flowing counter-current with the falling film. As a result the liquid solution temperature $\left(\mathrm{T}_{\mathrm{L}}\right)$ decreases along the absorber and the coolant fluid temperature $\left(\mathrm{T}_{\mathrm{C}, \mathrm{abs}}\right)$ increases. The interface temperature $\left(\mathrm{T}_{\text {int }}\right)$ is always slightly higher than the liquid solution onebecause of the absorption heat generated at the interface. Vapour phase temperature $\left(\mathrm{T}_{\mathrm{V}}\right)$ strongly increases at the top of the absorber and reaches interface temperature at a length of $254 \mathrm{~mm}$. Once the interface temperature is reached, heat transfers are reversed and vapour temperature decreases with liquid and interface temperatures. 


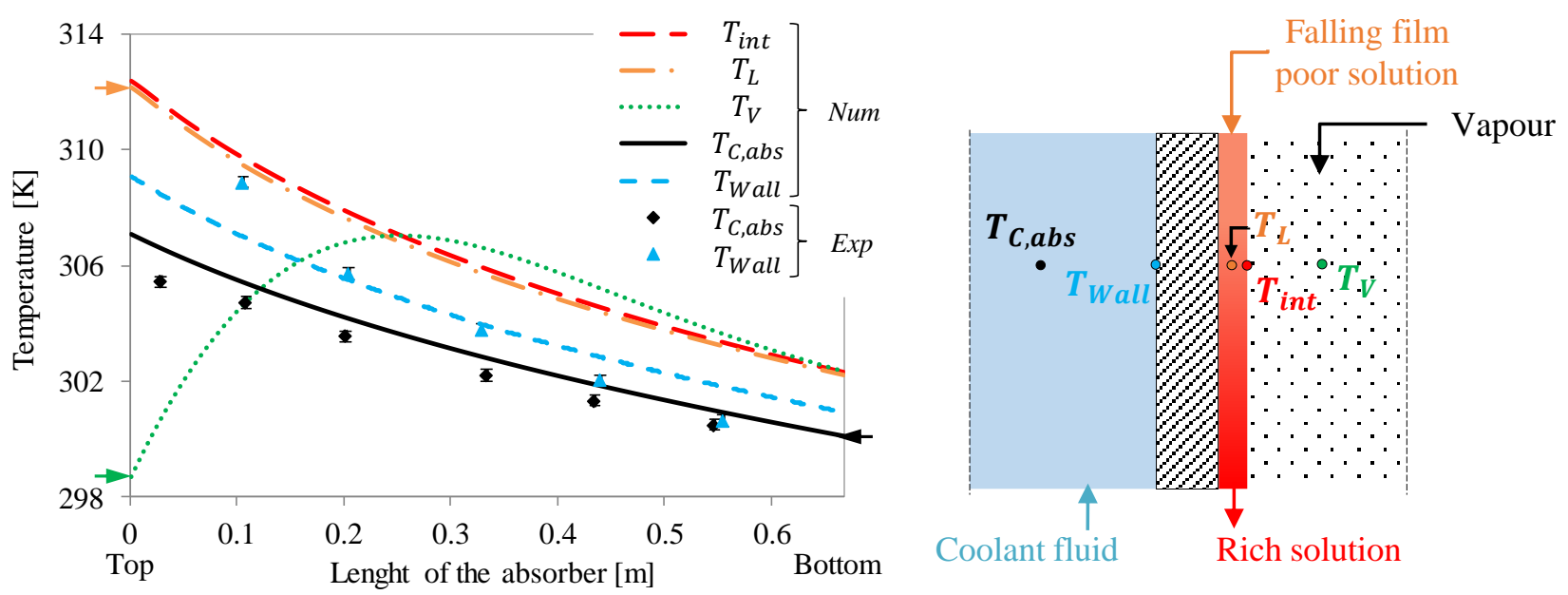

Fig. 10. Profile and diagram of temperatures along the absorber

Fig. 10. presents also experimental coolant fluid temperature measurements. A comparison between numerical and experimental values of $\mathrm{T}_{\mathrm{C} \text {,abs }}$ shows that absorption process is slightly overestimated in the numerical study but the trend of the temperature curves is the same.

Concerning wall temperatures, the trend of the temperature curves differs between experimental and numerical results. On the one hand, numerical values of wall temperatures show an absorption process which slowly decreases all along the absorber with a decreasing temperature difference between the coolant fluid and the wall. The absorption process seems to be a little more important at the top of the absorber. On the other hand, experimental values of wall temperatures show an absorption mass flux much more important at the top of the absorber. In this place, the difference between coolant fluid temperature and wall temperature is greater than the one at the bottom of the absorber (which is closed to zero).

This experimentalvalue of absorption mass flux at the top of the absorber could be explained by a lower wetted area at the bottom of the absorber because of a possible poor distribution of the liquid film in the experimental study.

However, these experimental wall temperature measurements must be cautiously interpreted:the metal adhesive used to keep temperature sensors on the plate for wall temperature measurements has a low valueof thermal conductivity (1.07 $\mathrm{W} / \mathrm{m} . \mathrm{K}$ ) and locally disturbs the heat flux around the thermocouples. The absorption heat flux can be overestimate because of the metal adhesive.

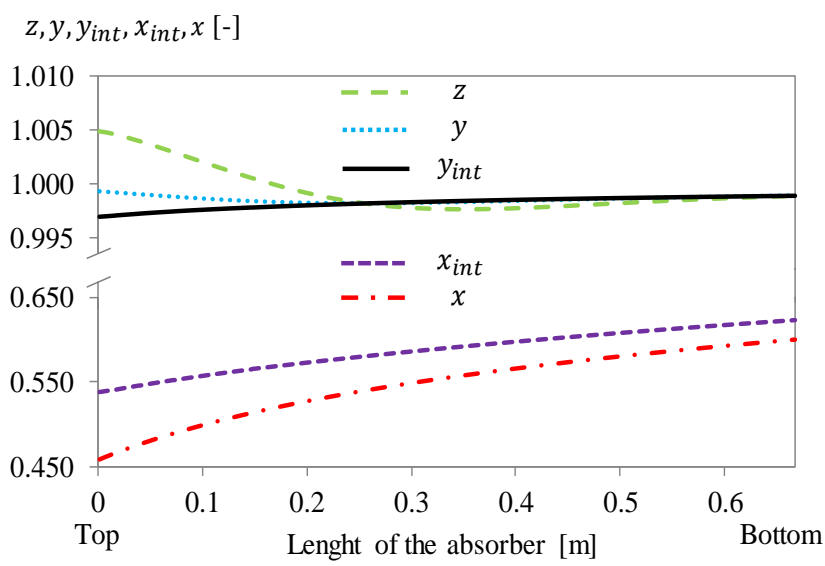

a)

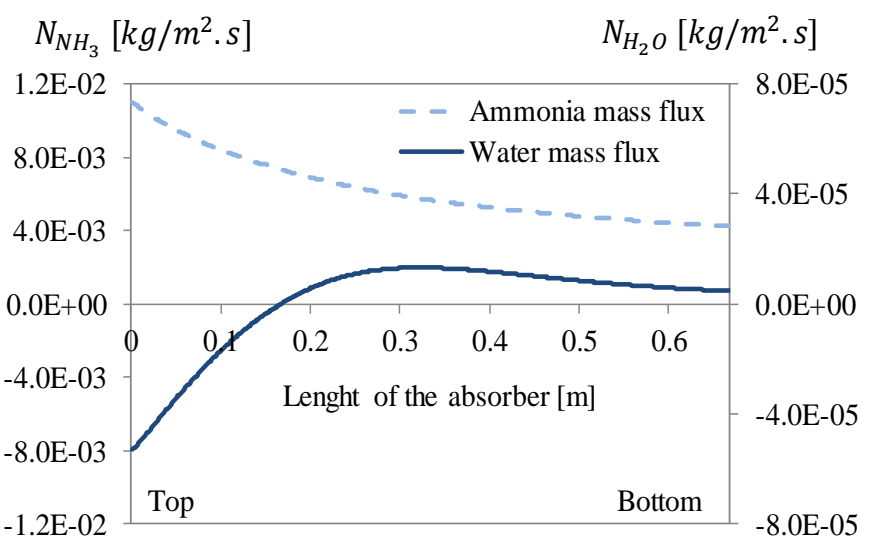

b)

Fig. 11. a) Variation of ammonia mass fraction along the absorber, b) Profile of absorbed / desorbed fluxes along the absorber.

Fig. 11.a. shows the evolution of ammonia mass fractions along the absorber. As explained before, $\mathrm{z}$ represents the ammonia mass fraction in the absorbed/desorbed flux. If $\mathrm{z}$ is superior to 1, water is desorbed from liquid to vapour $\left(N_{\mathrm{H}_{2} \mathrm{O}}<0\right)$ and if $\mathrm{z}$ is inferior to 1 , water is absorbed from vapour to liquid $\left(N_{\mathrm{H}_{2} \mathrm{O}}>0\right)$, but in all cases, ammonia is absorbed from vapour to liquid. The variation of exchanged mass fluxes along the absorber is presented in Fig. 11.b. Positive value of the ammonia mass flux indicates absorption of ammonia from vapour to liquid all along the absorber. Negative and positive values of the water mass flux indicate, firstly desorption of water from liquid to vapour and secondly absorption of water from vapour to liquid. Several studies confirm this desorption of water [18, 36].

At the top of the absorber, $\mathrm{z}$ is superior to 1 and superior to ammonia mass fraction in the vapour phase; moreover, ammonia mass fractionvaluein the vapour phase is higher than the one at vapour interface; therefore, because of the very 
low water mass fraction in the vapour phase, as previously stated,water is desorbed by diffusion process, ammonia is absorbed and ammonia mass fraction in vapour phase decreases (because the absorbed mass flux is more concentrated than the vapour phase).

Then, vapour ammonia mass fraction becomes lower than interface vapour ammonia mass fraction and $\mathrm{z}$ decreases and becomes lower than vapour ammonia mass fraction. This phenomenon is due to the decrease of the difference between $y$ and $\mathrm{x}$. The absorbed mass flux being less concentrated than the vapour phase, ammonia mass fraction increases in the vapour phase and ammonia and water are always absorbed in the liquid phase.

The interface vapour $\left(\mathrm{y}_{\text {int }}\right)$ and the interface liquid $\left(\mathrm{x}_{\text {int }}\right)$ ammonia mass fractions increase all along the absorber because of the reduction of the interface temperature.

Finally, all along the absorber, ammonia mass fraction of liquid solution (x) increases because of the high concentration of the absorbed flux compared to the liquid phase one.

The simulation results lead also to consider the limiting and governing effects of transfer resistances. The slight difference between interface temperature and liquid phase temperature all along the absorber (Fig. 10) indicates that the liquid-side heat transfer resistance is negligible compared to others heat transfer resistances. In the first part of the absorber, the temperature difference between the liquid film and the vapour phase is important, heat transfer to the vapour phase cannot be neglected despite a large heat transfer resistance in the vapour phase. In the second part of the absorber, as soon as the vapour phase reaches interface temperature, the coolant fluid governs heat transfer in the plate exchanger.

Regarding mass transfer resistance, Fig. 11.a. shows a larger ammonia mass fraction difference between the falling film and the liquid-vapour interface than between the vapour phase and the liquid-vapour interface. Therefore, the absorption process is controlled by the falling film mass transfer resistance. This conclusion about governing mass transfer resistance is also confirmed in differentfalling film absorber studies [18, 19].

\section{Parametric study}

A parametric analysis was performed to study the coolant mass flow rate impact on the absorber performances. Indeed, as mentioned earlier, experimental tests show an increase of the absorber performances when the coolant mass flow rate is higher. However, because absorber experimental inlet conditions vary during these tests, the coolant mass flow rate cannot be considered as the unique reason of this trend.

The variation of the absorber inlet parameters is due to the response of the chiller when the coolant mass flow rate is modified.

To dissociate the coolant mass flow rate impact from the inlet parameters impact, numerical simulations were carried out for different coolant mass flow rates with the same set of inlet parameters and for different sets of absorber inlet parameters at a steady coolant mass flow rate $\left(\dot{m}_{C, a b s}\right.$ Ref).

Table 6 summarizes the sets of absorber inlet parametersand the coolant mass flow rates of the 14 experiments considered for this parametric study. The set of inlet parameterscalled " $\mathrm{k}$ " is the reference set of inlet conditions.

Table 6. Set of operating conditions at the inlet of the absorber

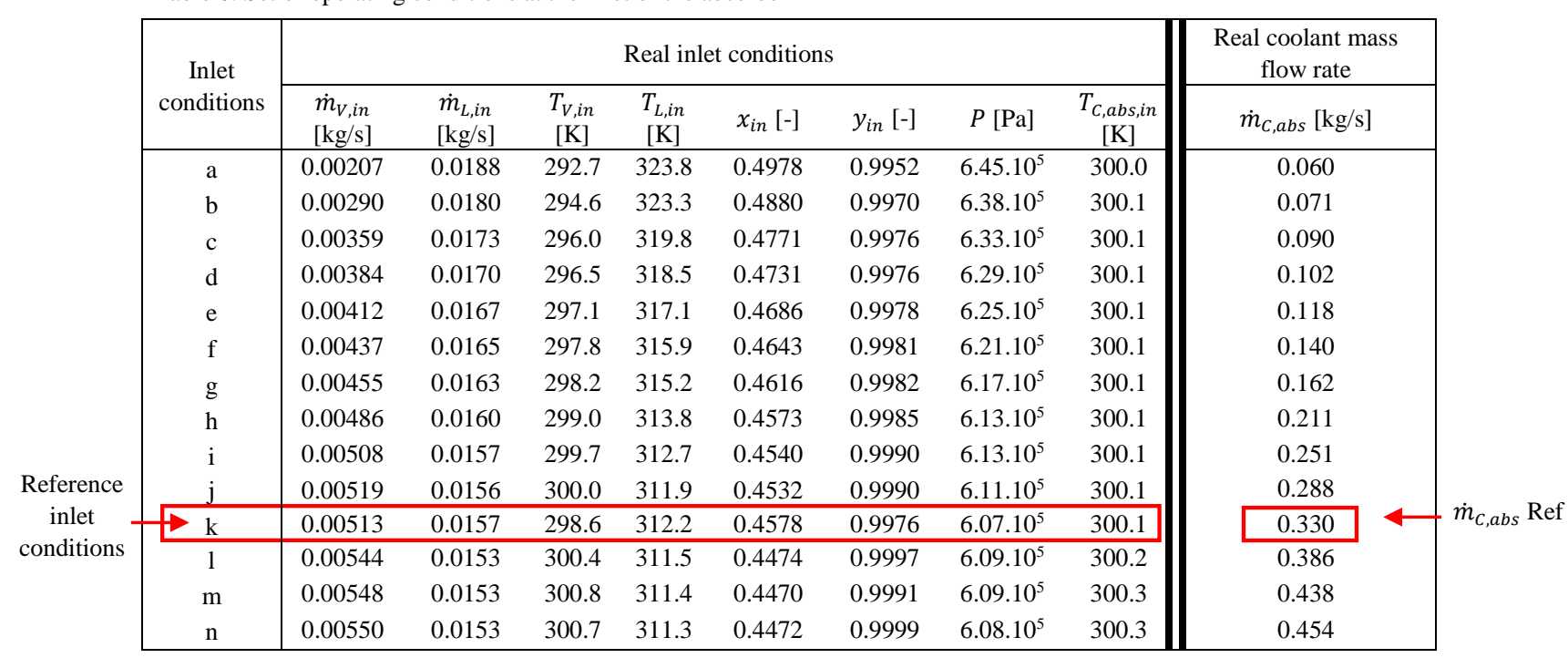




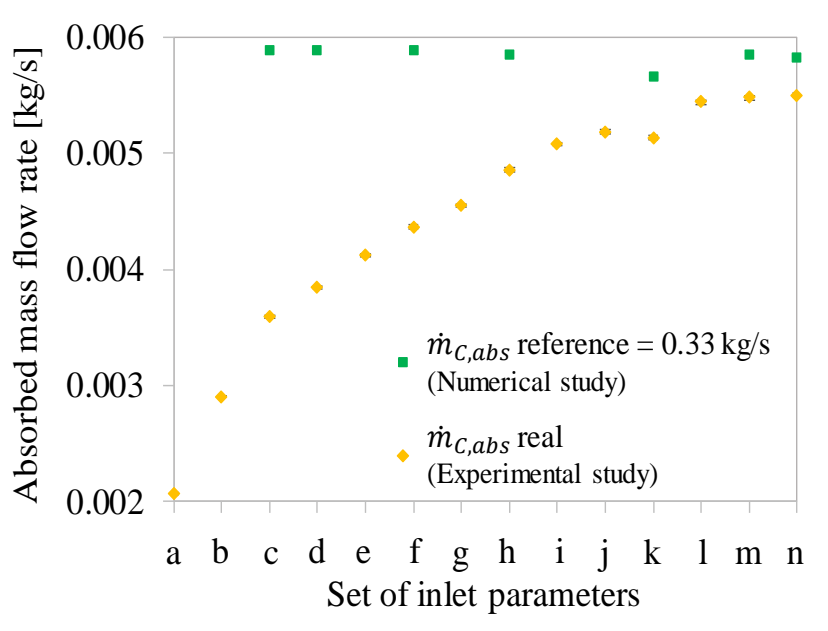

a)

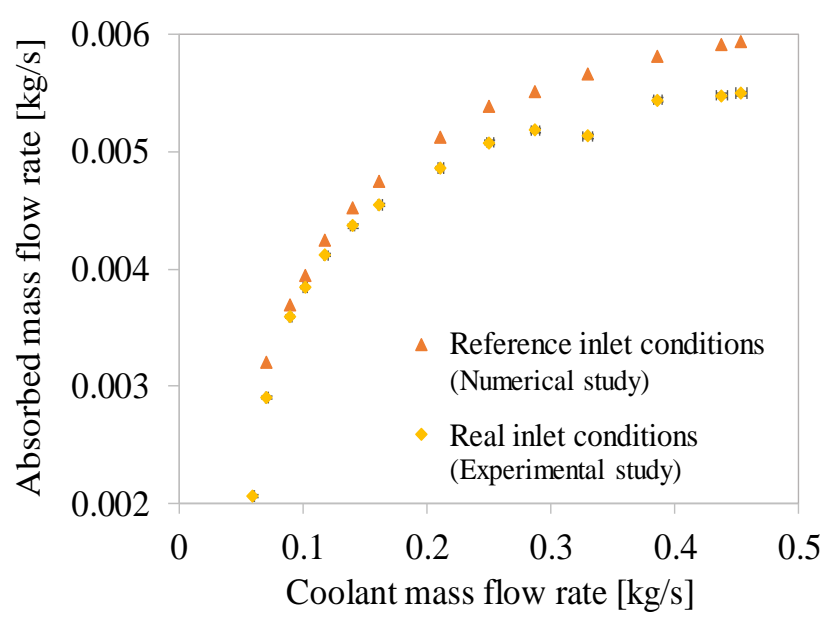

b)

Fig. 12. a) Absorbed vapour mass flow rate versus set of inlet parameters for different coolant mass flow rates and for reference coolant mass flow rate, b) Absorbed vapour mass flow rate versus coolant mass flow rate for different inlet conditions and for reference inlet conditions.

Fig. 12.a. and Fig. 12.b. present the absorbed vapour mass flow rate determined with experimental tests as a function of the set of inlet parameters on Fig. 12.a. and as a function of the coolant mass flow rate on Fig. 12.b.

Fig. 12.a. enables the comparison between experimental results and results of simulations which were achieved for different sets of absorber inlet conditions at the reference coolant mass flow rate (points with a scare shape). It indicates a very low difference of absorbed mass flow rate when the coolant mass flow rate is fixed while others inlet parameters change.

Fig. 12.b. makes possible the comparison between experimental results and numerical results which point out the variation of absorbed mass flow rate for different coolant mass flow rate at reference inlet conditions. The trend is almost the same for both curves if the model overestimation is neglected.

As a result, with the operating conditions and the absorber design used for this study,the impact of the coolant mass flow rate on the absorbed vapour mass flow rate is significant and predominant compared to the impact of the absorber inlet parameters induced by the rest of the absorption chiller.

\section{Conclusion}

The absorber being one of the most critical components of the absorption chiller, an analysisof heat and mass transfer in a falling film plate heat exchanger used as absorber was performed.

On the one hand, a fully instrumented ammonia-water absorption chiller prototype was used to experimentally study the absorber behaviour in real operating conditions. On the other hand, a numerical model was developed to analyse local phenomena along the absorber and to conduct parametric studies.

The experimental study focuses on the impact of the coolant fluid mass flow rate on the absorber performances. It shows the difficulty to experimentally analyse the behaviour of an absorber in a real absorption chiller. Indeed, test conditions at the input of the absorber are representative of real conditions but retroactive effects result in the impossibility to dissociate the impact of each parameter. So, the experimental study points out that a numerical model is required to perform a detailed study of the absorption process.

The developed model provides thermodynamic and transport properties along the absorber plates and enables to analyse heat and mass flows through the liquid-vapour interface. The model is validated with a comparison between experimental and numerical results which shows a maximal relative difference of $15 \%$. Observed overestimation in the numerical study could be explained by the inaccuracy of the assumption of totally wet exchange surface even though the assumption of flat plates tends to an underestimation of the exchange surface. Moreover, the corrugations can have a great influence on heat and mass transfer. These suppositions arelimitations of the study and additional researches will be conducted to analyse the validity of these assumptions.

The validation of the model has to be carry out over a wider range of operating conditions but it is already efficient to size an absorber.

Thanks to the detailed numerical analysis, the desorption of water is found at the top of the absorber. Moreover, the study showsthat the liquid-side heat transfer resistance is negligible compared to other heat transfer resistances and that during the absorption process, mass transfers are controlled by the falling film mass transfer resistance.

Then, a parametric analysis was performed to study the coolant mass flow rate impact on the absorber performances, to complete the experimental study. It is found that the coolant mass flow rate has a significant and predominant impact on the absorbed vapour mass flow rate compared to the impact of the absorber inlet parameters variation induced by the rest of the absorption chiller. 
To conclude, the model enables to study the behaviour of an absorber when the coolant mass flow rate varies, neglecting the parameters variation induced by the change of coolant mass flow rate.

Additionalparametric studies will be performed to study the impact of all control parameters on the absorber behaviour.

\section{References}

[1] M. Pons, G. Anies, F. Boudéhenn, P. Bourdoukan, J. Castaing-Lasvignottes and al, Performance comparison of six solar-powered air-conditioners operated in five places, Energy 46 (2012) 471-483.

[2] Global Market Study on Absorption Chillers: Increasing Demand for Renewable Energy Based Air-conditioning Systems to Drive Growth during Forecast Period, Persistence Market Research Pvt. Ltd. 2016.

[3] M. Mittermaier, F. Ziegler, Theoretical evaluation of absorption and desorption processes under typical conditions for chillers and heat transformers, International Journal of Refrigeration 59 (2015) 91-101.

[4] J. Ibarra-Bahena, R.J. Romero, Performance of different experimental absorber designs in absorption heat pump cycle technologies: A review, Energies 7 (2014) 751-766.

[5] J.M. George, S.S. Murthy, Influence of absorber effectiveness on performance of vapour absorption heat transformers, International Journal of Energy Research 13 (1989) 629-638.

[6] J. Cerezo, M. Bourouis, M. Vallès, A. Coronas, R. Best, Experimental study of an ammonia-water bubble absorber using a plate heat exchanger for absorption refrigeration machines, Applied thermal engineering 29 (2009) 1005-1011.

[7] J. Cerezo, R. Best, M. Bourouis, A. Coronas, Comparison of numerical and experimental performance criteria of an ammonia-water bubble absorber using plate heat exchangers, International Journal of heat and mass transfer 53 (2010) 3379-3386.

[8] D.E. Hartley, W. Murgatroyd, Criteria for the break-up of thin liquid layers flowing isothermally over solid surfaces, Int J. Heat Mass Transfer 7 (1964) 1003-1015.

[9] A.K. Nagavarapu, S. Garimella, Falling film absorption around microchannel tube banks, Journal of heat transfer 135 (122001) (2013) 1-10.

[10] S. Lee, L.K. Bohra, S. Garimella, A.K. Nagavarapu, Measurement of absorption rates in horizontal-tube falling-film ammonia-water absorbers, International Journal of Refrigeration 35 (2012) 613-632.

[11] M.D. Raisul Islam, N.E. Wijeysundera, J.C. Ho, Evaluation of heat and mass transfer coefficients for falling-films on tubular absorbers, International Journal of Refrigeration 26 (2003) 197-204.

[12] Y.T. Kang, R.N. Christensen, Development of a counter current model for a vertical fluted tube GAX absorber, Proceedings of the International absorption heat pump conference, AES-Vol 31, 1993, pp. 7-16.

[13] L. Harikrishnan, M.P. Maiya, S. Tiwari, Investigations on heat and mass transfer characteristics of falling film horizontal tubular absorber, International Journal of heat and mass transfer 54 (2011) 2609-2617.

[14] J. Fernandez-Seara, J. Sieres, C. Rodriguez, M. Vazquez, Ammonia-water absorption in vertical tubular absorbers, International Journal of thermal sciences 44 (2005) 277-288.

[15] N. Goel, D.Y. Goswami, Analysis of a counter-current vapor flow absorber, International Journal of Heat and Mass Transfer 48 (2005) 1283-1292.

[16] Y.T. Kang, A. Akisawa, T. Kashiwagi, Experimental correlation of combined heat and mass transfer for NH3-H2O falling film absorption, International Journal of refrigeration 22 (1999) 250-262.

[17] L.P. Kholpanov, E.Y. Kenig, W.A. Malyusov, Combined heat and mass transfer for opposing film flows of liquid and gas, Journal of Engineering Physics 51 (1) (1986) 768-773.

[18] H. Perez-Blanco, A model of an ammonia-water falling film absorber, ASHRAE Transactions, 1988, Vol 94-1, pp. 467-483.

[19] B. Kim, Heat and mass transfer in a falling film absorber of ammonia-water absorption systems, Heat transfer Engineering 19 (3) (1998) 53-63.

[20] I. Fujita, E. Hihara, Heat and mass transfer coefficients of falling-film absorption process, International Journal of heat and mass transfer 48 (2005) 2779-2786.

[21] M. Mittermaier, P. Schulze, F. Ziegler, A numerical model for combined heat and mass transfer in a laminar liquid falling film with simplified hydrodynamics, International Journal of heat and mass transfer 70 (2014) 990-1002.

[22] K. Gommed, G. Grossman, M.S. Koenig, Numerical study of absorption in a laminar falling film of Ammonia-Water, ASHRAE Transactions, 2001, pp. 453-462.

[23] J.D. Killion, S. Garimella, A critical review of models of coupled heat and mass transfer in falling-film absorption, International Journal of refrigeration 24 (2001) 755-797.

[24] K. Kwon, S. Jeong, Effect of vapor flow on the falling-film heat and mass transfer of the ammonia/water absorber, International Journal of refrigeration 27 (2004) 955-964.

[25] F. Boudéhenn, H. Demasles, J. Wyttenbach, X. Jobard, D. Chèse, P. Papillon,Development of a 5 kW cooling capacity ammonia-water absorption chiller for solar cooling applications, Energy Procedia 30 (2012) 35-43.

[26] A. Bontemps, Condensation de mélanges de vapeurs - Transfert de chaleur et de masse, Techniques de l'ingénieur, 2001, BE 9 910, pp. 1-13.

[27] R.E. Treybal, Mass Transfer Operations, McGraw-Hill, New York, 1980. 
[28] S.M. Yih, K.Y. Chen, Gas absorption into wavy and turbulent falling liquid films in a wetted-wall column, Chemical Engineering Communications, 1982, Vol 17, pp. 123-136.

[29] S. Kakaç, R.K. Shah, W. Aung, Handbook of single phase convective heat transfer, Wiley Interscience, 1987, chapter 3.

[30] R. Taylor, R. Krishna, Multicomponent Mass Transfer, John Wiley \& Sons, 1993.

[31] T.H. Chilton, A.P. Colburn, Mass Transfer (Absorption) Coefficients, Industrial and Engineering Chemistry 26 (11) (1934) 1183-1187.

[32] Groupement pour la Recherche sur les Echangeurs Thermiques, Manuel Technique du GRETh, 2010.

[33] W. Wilke, Wärmeübergang an Rieselfilme, VDI-Fors-chungsheft 490 (1962) B28.

[34] R. Tillner-Roth, D.G. Friend, Survey and assessment of available measurements on thermodynamic properties of the mixture "Water-Ammonia", Journal of Physical Chemistry 27 (1) (1998) 45-61.

[35] M. Conde, Thermophysical properties of ammonia-water mixtures for the industrial design of absorption refrigeration equipment, M. CONDE Engineering, 2006.

[36] Y.T. Kang, A. Akisawa, T. Kashiwagi., Analytical investigation of two different absorption modes: falling film and bubble types, International Journal of refrigeration 23 (2000) 430-443. 